\title{
EDITORIAL
}

\section{URBANIZATION AND AGEING HEALTH OUTCOMES}

\author{
J.-P. MICHEL \\ Corresponding author: Jean-Pierre Michel, Medical University of Geneva, Switzerland, Jean-pierre.michel@unige.ch, https://orcid.org/0000-0003-0718-4394
}

Key words: Urbanization, rural-urban migrants, pollution, health inequities, aged.

The world aging population is continuously rising. In 1950, the population of the world was 2.5 billion people (of whom 128 million were aged 65 years and over, accounting for $5 \%$ ). It reached 7.8 billion in 2020 (10\% of people aged 65+) and will continue to grow strongly, to peak at 9.7 billion in 2050 (with $16 \%$ aged $65+$ ) (1). During the same time period, the world's urban population has increased from 746 million in 1950 to 4 billion in 2020. By 2050, this number is expected to increase to 6.4 billion (2), meaning that two-thirds of the world's entire population will live in urban areas (3). In such conditions, it appears logical to anticipate what the impacts of urbanization on health might be, before also focusing on specific behavioral aspects and factors affecting well-being among the old population.

Urbanization is the process by which humans form dense settlements constructed of buildings, roads, and supporting infrastructure (4). Historically, urbanization was related to positive economic development and improved health, as cities generally offer better sanitation, opportunities for education and work, as well as good infrastructure and health services (4). However, the current urbanization process is totally different, due to rapid and unstructured in-migration of people to cities. This important social process underpinning the dynamics of human society is especially impactful in the 21 st century, with profound repercussions for natural and built infrastructures, as well as environmental health and human well-being $(2,5)$.

Major urbanization totally alters the natural and biotic environment due to deforestation, fragmented habitation, loss of phylogenetic heterogeneity and declines in the number and diversity of native species (6). Urbanization, with new buildings, more roads, more cars, higher ambient temperature provokes air, noise and light pollution. These physical changes in the abiotic environment create a novel ecosystem in cities, in which numerous non-native species (rabies, bird flu, Ebola, zika, chikungunya, dengue, rickettsiosis, leptospirosis and others) may start to proliferate, due to their adaptative ability in response to new physical city structures, pesticide use, pollution and increased local climate (6). The emergence or re-emergence of these species raises challenging prevention issues and increase antimicrobial resistance.

Urbanization boosts temperatures, and this in turn brings on two major types of effect:

- The urban heat island effect and thermal stress, whose consequences include proliferation of waterborne pathogens and carrying vectors;

- Extreme rainfall and widespread floods, which impacts insect breeding sites, drives rodents out of burrows and contaminate clean water systems.

Both phenomena may provoke outbreaks of infectious diseases, and increase human morbidity (especially epidemics, which alter physical and mental health) and mortality (5).

Other features of urbanization, especially road transportation, indoor combustion, greenhouse gases, smoke emissions from factories etc, alter the ambient air, with less primary natural particulates and glut episodes of production of secondary particulates (PM $10[<10 \mu \mathrm{M}]$ and PM $2.5[<$ $2.5 \mu \mathrm{M}])$ (7). This can exacerbate asthma, lead to impaired lung function (COPD, lung cancer), increased cardiovascular morbidity, unhealthy ageing (8) and indeed increased mortality $(7,8)$.

The alteration of the natural environment and the uncontrolled expansion of urban areas favour water pollution, which, combined with inadequate sanitation, together favour parasitic infections provoking diarrhoea and acute and chronic gastro-intestinal diseases (9). The greatest threats to health linked to pollution from contaminated, unregulated local artisanal or industrial activities are related to the persistence in the soil of metals (lead, mercury, chromium, and cadmium), organic pollutants (including pesticides) and radionuclides (9). The scarcity of surface water resources combined with the overapplication of pesticides and chemical pollutants also have a dramatic impact on food safety and increase the carcinogenic risks $(10,11)$.

All these types of pollution related to excessive urbanization have negative repercussions on the ageing process. However, the biggest culprit is air pollution, which has immediate health consequences on respiratory health, while noise pollution alters mental health, and water/soil pollution has more insidious consequences for current and future ageing generations.

The fallout from urbanization on health is not only linked to climate change and increased pollution. Urbanization also modifies daily behaviours, which alter the ageing process and affect wellness among old adults.

Regardless of age, migration from rural to urban areas is driven by inequality in development. Migrants are profoundly 


\section{URBANIZATION AND AGEING HEALTH OUTCOMES}

marked by events that occurred during their infancy and young adult life (such as having a low education level, poor material living conditions, inappropriate sanitation and poor psychosocial conditions), which contribute to their decision to migrate. Only the healthiest and most educated are more likely to migrate. However, the accumulation of past social advantages or disadvantages will modify their own ageing process throughout life, regardless of how well and how quickly they adapt to their new urban life (12). Irrespective of their personality or how they might wish to integrate (or not), the adaptation of migrants to a new city depends on the neighbouring social, physical and emotional environment that they integrate. Networks of family members and friends are essential to re-starting a social life (13). Unfortunately, without these initial human links, rural-to-urban migrants may have difficulty establishing and maintaining meaningful relations with other people. They may end up living as lone individuals in the city (2) or in disadvantageous surroundings, which fosters social isolation and hampers their ability to maintain ties or form new relationships (13).

The stress linked to the life upheaval experienced by rural-to-urban migrants is enormous, and it is compounded by the need to respect local governmental policy, city and employer's rules, if they have been lucky enough to find a job. Generally, rural-urban migrants have better physical health and better socioeconomic status than rural natives, but nonetheless have inferior conditions to urban natives, because they more frequently occupy less well paid occupations, such as manufacturing and construction (12). Too often, a high workload and poor regard for working conditions accentuate the difficult living situation, and negatively affect nutritional habits $(14,15)$. Together with an increase in sedentary lifestyle (16), this toxic "cocktail" equates to a distressful life, which will greatly alter health and the ageing process itself (17, 18). Life uncertainty, higher levels of depressive and anxiety symptoms, pessimistic views toward life in general may generate psychological distress with drug abuse, violence and crime (19).

As described above, the urban environment for rural-tourban migrants has measurable consequences that are associated with less apparent, but essential issues. Ageing migrants frequently perceive that they are no longer an integral part of the family they voluntarily left. They may feel that they no longer wield any authority, and have become useless in family decision-making, which can undermine their personal emotional life and well-being (18). The results of such an accumulation of negative factors are visible in the increased number of suicides, especially in female rural-urban migrants, starting at midlife and increasing until very old age (20). Another poor outcome of such rural-urban migrations is the increased prevalence of cognitive impairment and dementia in older urban adults compared to those who stay living in rural areas (respectively 1.88 vs. 0.80 and 1.54 vs. 0.68$)(21)$.

It is clear that the absence of family relationship and family care, coupled with the loss of social support, greatly impacts on the health and well-being of rural-to-urban migrants. Without a doubt, social organizations, neighbourhood centres and healthcare professionals all have a role to play in promoting health, a successful ageing process, and wellbeing among rural-urban migrants. It would be an oversight to close this editorial without mentioning the old parents of rural-urban migrants who are left behind, and who are socially penalized, due to their reduced functional support and increased psychosocial isolation. This will also impact on their health in the late phase of their life (22).

To conclude, it appears that in accordance with the WHO and UN Habitat's report "Hidden Cities", all urban environments have the ability to produce health inequities that are "systematic, socially produced, and unfair" (23) which contribute to unhealthy ageing.

Disclosure: The authors have no conflicts of interest.

\section{References}

1. UN Data. Population. Available at: https://data.un.org/Search.aspx?q=population [Access date: 6 April 2020]

2. Okkels N, Kristiansen CB, Munk-Jorgensen P, Sartorius N: Urban mental health: challenges and perspectives. Curr Opin Psychiatry 2018, 31(3):258-264.

3. United Nations General Assembly: Draft outcome document of the United Nations Conference on Housing and Sustainable Urban Development (Habitat III). In 2016: http://habitat3 .org/wp-content/uploads/NUA-English.pdf [Access date: 6 April 2020].

4. United Nations Department of Economic and Social Affairs: World Urbanization Prospects. The 2018 Revision. Available at: https://population.un.org/wup/ Publications/Files/WUP2018-Report.pdf [Access date: 6 April 2020]. In. New York, NY.; 2019.

5. Li X, Song J, Lin T, Dixon J, Zhang G, Ye H: Urbanization and health in China, thinking at the national, local and individual levels. Environ Health 2016, 15 Suppl $1: 32$.

6. Johnson MTJ, Munshi-South J: Evolution of life in urban environments. Science 2017, 358(6363)

7. Fougere B: [Role of aging and smoking in the modulation of genotoxic and epigenetic events of carcinogenesis after exposure to air pollution particulate matter]. University of the Littoral Opal Coast; 2014.

8. Giles-Corti B, Vernez-Moudon A, Reis R, Turrell G, Dannenberg AL, Badland H, Foster S, Lowe M, Sallis JF, Stevenson M et al: City planning and population health: a global challenge. Lancet 2016, 388(10062):2912-2924.

9. Landrigan PJ, Fuller R, Acosta NJR, Adeyi O, Arnold R, Basu NN, Balde AB, Bertollini R, Bose-O'Reilly S, Boufford JI et al: The Lancet Commission on pollution and health. Lancet 2018, 391(10119):462-512.

10. Lu Y, Song S, Wang R, Liu Z, Meng J, Sweetman AJ, Jenkins A, Ferrier RC, Li H, Luo W et al: Impacts of soil and water pollution on food safety and health risks in China. Environ Int 2015, 77:5-15.

11. Zhu Q, Yao Y, Ning CX, Zhao YL: Trace Element Levels in the Elders over 80 from the Hainan Province of China. J Nutr Health Aging 2019, 23(9):883-889.

12. Hou B, Nazroo J, Banks J, Marshall A: Impacts of migration on health and well-being in later life in China: Evidence from the China Health and Retirement Longitudinal Study (CHARLS). Health Place 2019, 58:102073.

13. Cornwell EY, Behler RL: Urbanism, Neighborhood Context, and Social Networks. City Soc (Wash) 2015, 14(3):311-335.

14. Wyka J, Biernat J, Kiedik D: Nutritional determination of the health status in Polish elderly people from an urban environment. J Nutr Health Aging 2010, 14(1):67-71.

15. Wham C, Carr R, Heller F: Country of origin predicts nutrition risk among community living older people. J Nutr Health Aging 2011, 15(4):253-258.

16. Lien WC, Chang JH, Guo NW, Lin YC, Hsieh PC, Kuan TS: Determinants of Perceived Physical Environment Barriers among Community-Dwelling Elderly in Taiwan. J Nutr Health Aging 2015, 19(5):575-582.

17. Xu F, Cohen SA, Lofgren IE, Greene GW, Delmonico MJ, Greaney ML: Relationship between Diet Quality, Physical Activity and Health-Related Quality of Life in Older Adults: Findings from 2007-2014 National Health and Nutrition Examination Survey. J Nutr Health Aging 2018, 22(9):1072-1079.

18. Gao S, Dupre K, Bosman C: Understanding the neighbourhood environment and the health and wellbeing of older Chinese immigrants: a systematic literature review. 


\section{THE JOURNAL OF NUTRITION, HEALTH \& AGING}

Ageing and Society 2019:1-21.

19. Luciano M, De Rosa C, Del Vecchio V, Sampogna G, Sbordone D, Atti AR, Bardicchia F, Bertossi F, Calo S, Cava L et al: Perceived insecurity, mental health and urbanization: Results from a multicentric study. Int J Soc Psychiatry 2016, 62(3):252-261.

20. Sha F, Yip PS, Law YW: Decomposing change in China's suicide rate, 1990-2010: ageing and urbanisation. Inj Prev 2017, 23(1):40-45.

21. Wu YT, Prina AM, Jones A, Barnes LE, Matthews FE, Brayne C, Mrc C: Micro-scale environment and mental health in later life: Results from the Cognitive Function and Ageing Study II (CFAS II). J Affect Disord 2017, 218:359-364.
22. Falkingham J, Qin M, Vlachantoni A, Evandrou M: Children's migration and lifestyle-related chronic disease among older parents 'left behind' in india. SSM Popul Health 2017, 3:352-357.

23. World Health Organization \& United Nations Human Settlements Programme: Hidden cities: unmasking and overcoming health inequities in urban settings. https:// apps.who.int/iris/handle/10665/44439 [Access date: 6 April 2020]. In.; 2010. 